\title{
The Histamine H4 Receptor Regulates Chemokine Production in Human Natural Killer Cells
}

\author{
Susanne Mommert ${ }^{\mathrm{a}}$ Oliver Dittrich-Breiholz ${ }^{\mathrm{b}}$ Holger Stark $^{\mathrm{c}}$ Ralf Gutzmer ${ }^{\mathrm{a}}$ \\ Thomas Werfel ${ }^{\mathrm{a}}$ \\ ${ }^{a}$ Department of Dermatology and Allergy, Division of Immunodermatology and Allergy Research, \\ Hannover Medical School, and ' Institute of Physiological Chemistry, Hannover Medical School, Hannover, and \\ 'Institute of Pharmaceutical and Medicinal Chemistry, Heinrich Heine University, Düsseldorf, Germany
}

\section{Key Words}

Histamine $\cdot$ Histamine $\mathrm{H} 4$ receptor $\cdot$ Chemokines

\begin{abstract}
Background: Natural killer (NK) cells have been detected in the lesional skin of patients with inflammatory skin diseases, where high levels of histamine are also present. Therefore, we investigated the effect of histamine, in particular via the histamine $\mathrm{H} 4$ receptor (H4R), on gene expression levels in human NK cells. Methods: Comprehensive microarraybased mRNA expression profiling was performed to assess the gene expression levels in human NK cells in response to H4R stimulation in an unbiased approach. The expression of selected cytokines and chemokines was quantified by realtime PCR and enzyme-linked immunosorbent assay. Results: The microarray analysis identified only few genes which were differentially regulated upon $\mathrm{H} 4 \mathrm{R}$ stimulation. In follow-up studies, a significant upregulation of CCL3 and CCL4 at the mRNA level and in addition for CCL3 also at the protein level via the H4R was observed. Conclusion: The elevated expression levels of chemokines in response to H4R stimulation might foster the inflammation in allergic skin diseases and characterize the H4R as a promising therapeutic target.
\end{abstract}

(c) 2015 S. Karger AG, Basel
(C) 2015 S. Karger AG, Base

$1018-2438 / 15 / 1663-0225 \$ 39.50 / 0$

\section{Introduction}

Human natural killer (NK) cells were discovered more than 30 years ago as innate immune effector cells with the unique capacity to affect virally infected, nonself eukaryotic and malignant cells without prior sensitization. The relative expression of the NK cell marker CD56 distinguishes the CD56 ${ }^{\mathrm{dim}} \mathrm{NK}$ cells which are characterized by strong cytotoxic capacity from the CD56 ${ }^{\text {bright }} \mathrm{NK}$ cells which represent the immunoregulatory subset by releasing a wide range of cytokines and chemokines in case of activation $[1,2]$. Peripheral NK cell levels were significantly reduced in patients with chronic inflammatory skin diseases such as psoriasis and atopic dermatitis compared to healthy subjects [3]. Interestingly, an increase of circulating NK cell numbers has been observed during acute psychosocial stress in atopic dermatitis patients [4]. Under inflammatory conditions, NK cells are activated to extravasate to tissues. In psoriatic skin, CD56 ${ }^{\text {bright }}$ lymphocytes were detected in the mid dermis as part of the cellular infiltrate [5]. Beside natural killer T cells [6], NK cells were detected in lesional skin from patients with allergic skin diseases as well [7].

In lesional skin of atopic dermatitis and psoriasis, high amounts of histamine are present $[8,9]$. Histamine is

\section{KARGER 125}

E-Mail karger@karger.com www.karger.com/iaa
Correspondence to: Dr. Susanne Mommert Department of Dermatology and Allergy Division of Immunodermatology and Allergy Research, Hannover Medical School Carl-Neuberg-Strasse 1, DE-30625 Hannover (Germany)

E-Mail Mommert.Susanne@mh-hannover.de 
known to be an important immunomodulatory mediator and elicits a broad array of physiological or pathophysiological responses by acting via $4 \mathrm{G}$ protein-coupled receptors, which are functionally expressed on many immune cells involved in inflammatory skin diseases [1014].

The expression of the H1R and H4R at the protein level on NK cells has been described previously. Moreover, migration of NK cells induced by histamine has been shown. Thioperamide, an antagonist of the H3R and H4R, abolished this effect. Since NK cells lack the expression of the H3R, the chemotaxis of NK cells was specifically attributed to the H4R [11].

However, immunomodulatory effects of histamine via the H4R on NK cells have not been described until now; therefore, we investigated the influence of the H4R on gene expression in NK cells in an unbiased approach.

\section{Materials and Methods}

\section{NK Cell Isolation}

Peripheral blood mononuclear cells were separated from buffy coats by density gradient centrifugation on Lymphoprep (Fresenius Kabi Norge AS, Oslo, Norway) as described previously [12]. Untouched CD3- and CD56+ NK cells were isolated by negative selection using magnetic beads, and the purity of the enriched NK cells was evaluated according to the manufacturer's instructions (Miltenyi Biotech Inc., Bergisch-Gladbach, Germany).

\section{Microarray-Based mRNA Expression Analysis (Dual Color}

Mode)

Isolated NK cells were resuspended at $5 \times 10^{5}$ cells $/ 200 \mu \mathrm{l}$ in modified Iscove medium containing $20 \mathrm{ng} / \mathrm{ml} \mathrm{IL}-2$. After $24 \mathrm{~h}$, the cells were stimulated with ST1006 $10^{-5} \mathrm{M}$ (H4R agonist, Institute of Pharmaceutical and Medicinal Chemistry, Heinrich Heine University, Germany) [13] or left unstimulated for $6 \mathrm{~h}$. RNA was isolated using the Qiagen RNeasy Microkit (Qiagen, Hilden, Germany).

The mRNA expression profiling was performed using the Whole Human Genome Oligo Microarray V2 (G4845A, ID 026652, Agilent Technologies) which contains 44,495 oligonucleotide probes covering roughly 27,390 human transcripts (a detailed protocol can be retrieved upon request). H4R-stimulated and -unstimulated samples, each pooled from 2 healthy donors, were labeled with different fluorophores (Alexa555 vs. Alexa647) and were cohybridized onto 1 microarray. A second microarray experiment, designed in a dye-swap approach, containing pooled samples from 2 further donors, was additionally conducted.

\section{NK Cell Stimulation}

Isolated NK cells were resuspended at $5 \times 10^{5}$ cells $/ 200 \mu \mathrm{l}$ in modified Iscove medium containing $20 \mathrm{ng} / \mathrm{ml} \mathrm{IL-2.} \mathrm{After} 24 \mathrm{~h}$, the cells were stimulated with histamine $10^{-5} \mathrm{M}$ (Alk-Scherax, Wedel, Germany) or ST1006 $10^{-5} \mathrm{M}$ for $6 \mathrm{~h}$ for quantitative PCR and $24 \mathrm{~h}$ for ELISA or were left unstimulated. For blocking ex- periments, the selective H4R antagonist JNJ7777120 $10^{-5} \mathrm{M}$ (Sigma-Aldrich, Deisenhofen, Germany) was added $30 \mathrm{~min}$ before stimulation.

\section{LightCycler Quantitative Real-Time PCR}

The isolation of RNA from NK cells, the reverse transcription and the LightCycler quantitative real-time PCR with primers designed by Qiagen were performed as described previously [12].

\section{ELISA}

Cell-free supernatants were used to detect the human chemokines CCL3 and CCL4 in ELISA, performed according to the manufacturer's instructions (R\&D Systems, San Diego, Calif., USA).

\section{Statistics}

For statistical analyses, the software GraphPad Prism version 5.0 was used. Wilcoxon's matched-pairs test was performed, and the medians are shown in figure 2 . A p value $<0.05$ was regarded as statistically significant.

\section{Results}

In a previous study, the expression of the H1R and H4R in human NK cells was already determined at the protein level [11]. Here, we detected the expression of the H1R, H2R and H4R but not H3R at the mRNA level on purified human NK cells (fig. 1a) by real-time LightCycler PCR (fig. 1b).

In order to identify genes which were regulated via the $\mathrm{H} 4 \mathrm{R}$, a comprehensive analysis of the mRNA expression of H4R-stimulated versus nonstimulated human NK cells was performed. Applying different filter criteria revealed only few genes to be differentially regulated upon H4R stimulation. Furthermore, observed differences in mRNA expression levels turned out to be just moderate. Only 17 out of 27,390 analyzed transcripts were differentially expressed after H4R stimulation, assessed by lowstringency filter criteria. Table 1 shows a repertory of these genes.

Since these genes are not of major known impact on NK cell functions, we selected genes of cytokines and chemokines which were analyzed in the same mRNA array and are known for having a role in NK cell activation as depicted in figure $2 a$. The mRNA of TNF- $\alpha$, CCL3, CCL4 and CCL3L3 showed slightly increased expression levels upon stimulation via H4R (fig. 2a). Of note, the homology in the complete gene region in chromosome 17q12 of CCL3L3 and CCL3 is $92.1 \%$ and in the exonic sequences $95.7 \%$, respectively [15].

We next analyzed the mRNA expression of TNF- $\alpha$, CCL3, CCL4 and CCL3L3 in NK cells, obtained from multiple donors, by quantitative real-time PCR. We ob- 


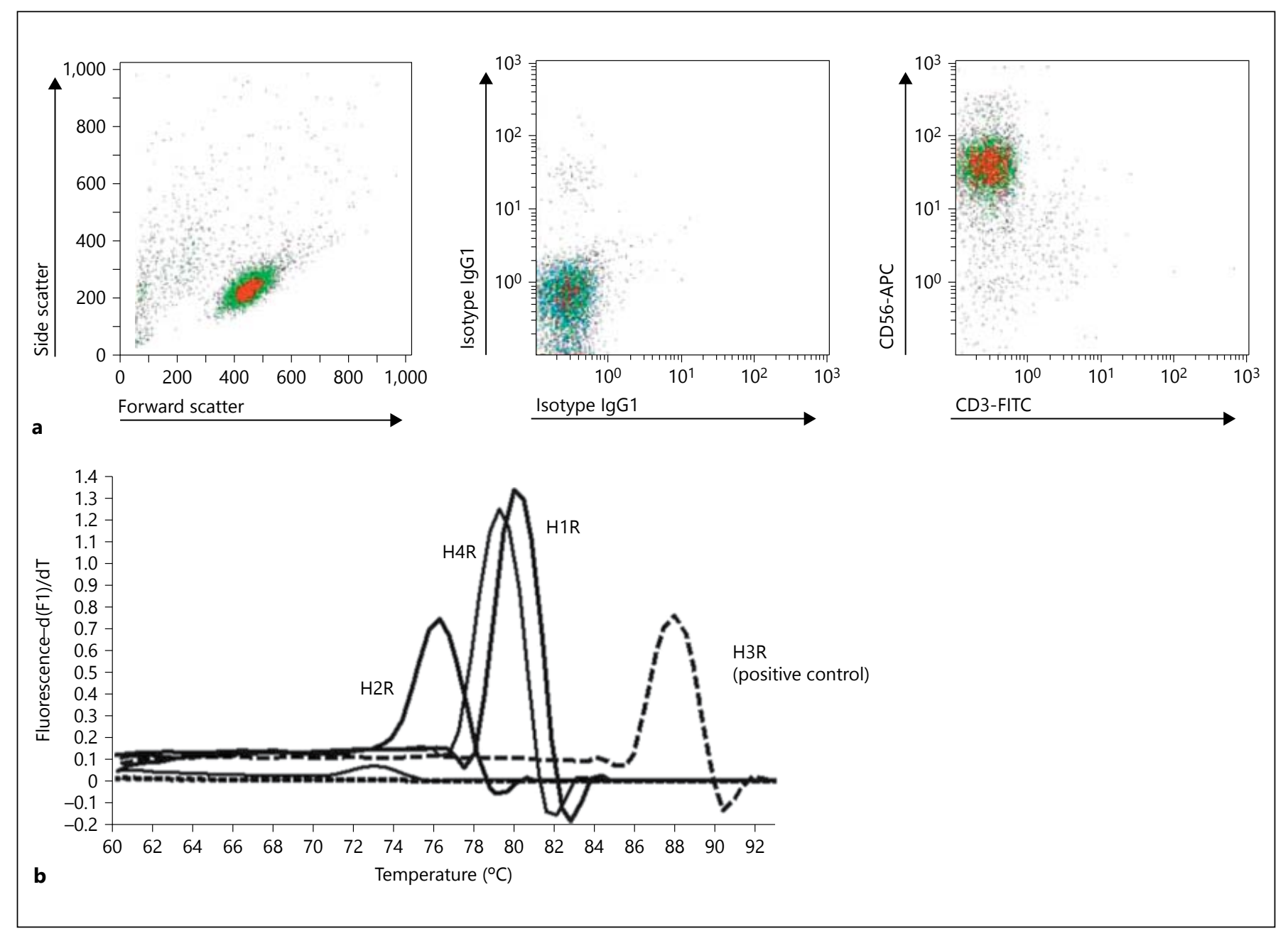

Fig. 1. a Evaluation of NK cell purity by flow cytometric analysis. One representative flow cytometric analysis plot showing NK cells as CD56+ and CD3- cells, the respective isotype controls and forward versus side scatter. b Human NK cells express the H1R, H2R and H4R mRNA but not the H3R mRNA. One representative realtime PCR out of 3 with melting peaks for each receptor is depicted. Complementary DNA of H3R-transfected HEK cells was used as positive control for the H3R PCR. served a significant upregulation of the mRNA expression of CCL4 and CCL3 upon stimulation with histamine or ST1006 (fig. 2b-d), whereas no change of the mRNA expression of CCL3L3 and TNF- $\alpha$ was detected (data not shown). To analyze the time dependence of the H4R-induced CCL3 mRNA expression, NK cells were treated either with histamine or ST1006 for different time periods. CCL3 mRNA expression increased significantly after 4,6 and $8 \mathrm{~h}$ with a peak at $6 \mathrm{~h}$ (fig. $2 \mathrm{c}$ ). The maximum mRNA expression level after $6 \mathrm{~h}$ in response to the H4R agonist ST1006 was also shown for CCL4 by investigating a smaller sample size (see online suppl. fig. S1d; for all online suppl. material, see www.karger.com/ doi/10.1159/000381340). We could also show that stim- ulation with ST1006 led to a significant upregulation of CCL3 at the protein level (fig. 2e). The increase of CCL3 protein was selectively abrogated after blocking the H4R with the specific antagonist JNJ7777120. No regulation of CCL4 protein secretion was detected upon H4R stimulation (data not shown).

Interestingly it was observed that IL-2, which was added to the culture medium to activate the NK cells, represents a strong inducer of the CCL3 mRNA expression and protein production when compared to the nonactivated resting NK cells. In addition, IL-2 was also essential for the upregulation of CCL3 mRNA expression and protein production by histamine or ST1006 (see online suppl. fig. S1a-c). As opposed to CCL3, the CCL4 mRNA expres- 
Table 1. Selection of genes regulated via the H4R in human NK cells after low stringency filtering grouped into functional categories

\begin{tabular}{llll}
\hline Gene name & Gene accession ID & Description & $\begin{array}{c}\text { n-fold } \\
\text { change }\end{array}$ \\
\hline $\begin{array}{l}\text { Cytokines/chemokines } \\
\text { CCL3L3 }\end{array}$ & NM_001001437 & Chemokine ligand 3-like 3 & 1.62 \\
\hline $\begin{array}{l}\text { Growth factors } \\
\text { AREG }\end{array}$ & NM_001657 & Amphiregulin & 1.78 \\
\hline Enzymes & & & 0.57 \\
BFSP1 & NM_001195 & Filament structural protein 1 & 0.50 \\
GBE1 & NM_000158 & 1,4-a-glucan branching enzyme 1 & 1.63 \\
PDE9A & NM_002606 & Phosphodiesterase 9A & 0.45 \\
\hline Kinases & & & 0.47 \\
AK4 & NM_001005353 & Adenylate kinase 4 & \\
PFKFB4 & NM_004567 & 6-phosphofructo-2-kinase/fructose-2,6-biphosphatase 4 & 0.47 \\
\hline Others & & & 0.47 \\
ADM & NM_001124 & Adrenomedullin & 1.55 \\
ITM2C & NM_030926 & Integral membrane protein 2C & 3.30 \\
NXPH4 & NM_007224 & Neurexophilin 4 & 0.54 \\
\hline VIT & NM_053276 & Vitrin & \\
\hline
\end{tabular}

Applied filter criteria were: $\mathrm{n}$-fold change $>1.5$ (or $<0.67$ ); arithmetic mean of processed signal values $>50$; IsFeatNonUnifOL $=0$ (all criteria to be fulfilled in both independent microarray experiments). The average $n$ fold change from 2 experiments is given.

sion was not influenced by IL-2. However, in the same way the presence of IL-2 was essential for the upregulation of the CCL4 mRNA expression via the H4R (see online suppl. fig. S1d). In addition, IL-2 upregulates CCL4 protein production (see online suppl. fig. S1e, f).

\section{Discussion}

Atopic dermatitis is a common inflammatory skin disease in which the role of the adaptive immune system, in particular of T lymphocytes, in the initiation and progression of the disease is well documented. NK cells, phenotypically characterized as CD3- and CD56+ lymphocytes, showed reduced frequency in the peripheral blood of atopic dermatitis patients. In contrast, their number is increased in the lesional skin of these patients [7]. Histamine, which is mainly released by activated mast cells, is known to be present in inflamed skin [8]. A previous study [11] has shown that histamine influences the migration of NK cells via the H4R but does not affect the cytotoxic capacity or the release of $\mathrm{Ca}^{2+}$ from NK cells.
Here, we investigated for the first time the expression of the histamine receptors, in particular of the H4R, at mRNA level and evaluated the role of the H4R on gene expression in human NK cells. We could show that the H1R, H2R and H4R mRNA, but not the H3R mRNA, are expressed in human NK cells. Comprehensive mRNA expression profiling after $\mathrm{H} 4 \mathrm{R}$ stimulation revealed only few genes to be differentially expressed. We focused our attention on selected targets, in particular the chemokines CCL3 and CCL4, which play a crucial role in the coordination of NK cell effector functions [16]. CCL3 and CCL4 showed increased mRNA expression levels in response to the H4R agonist in microarray analysis. These data were confirmed by subsequent mRNA and protein quantification from stimulated NK cells derived from multiple donors. These follow-up studies confirmed a significant upregulation of CCL3 and CCL4 mRNA expression in a time-dependent manner. Furthermore, we could show a significant upregulation only for CCL3 at the protein level in response to the H4R agonist, which was blocked by preincubation of the cells with a selective H4R antagonist, showing that the effect was specific for the H4R. 


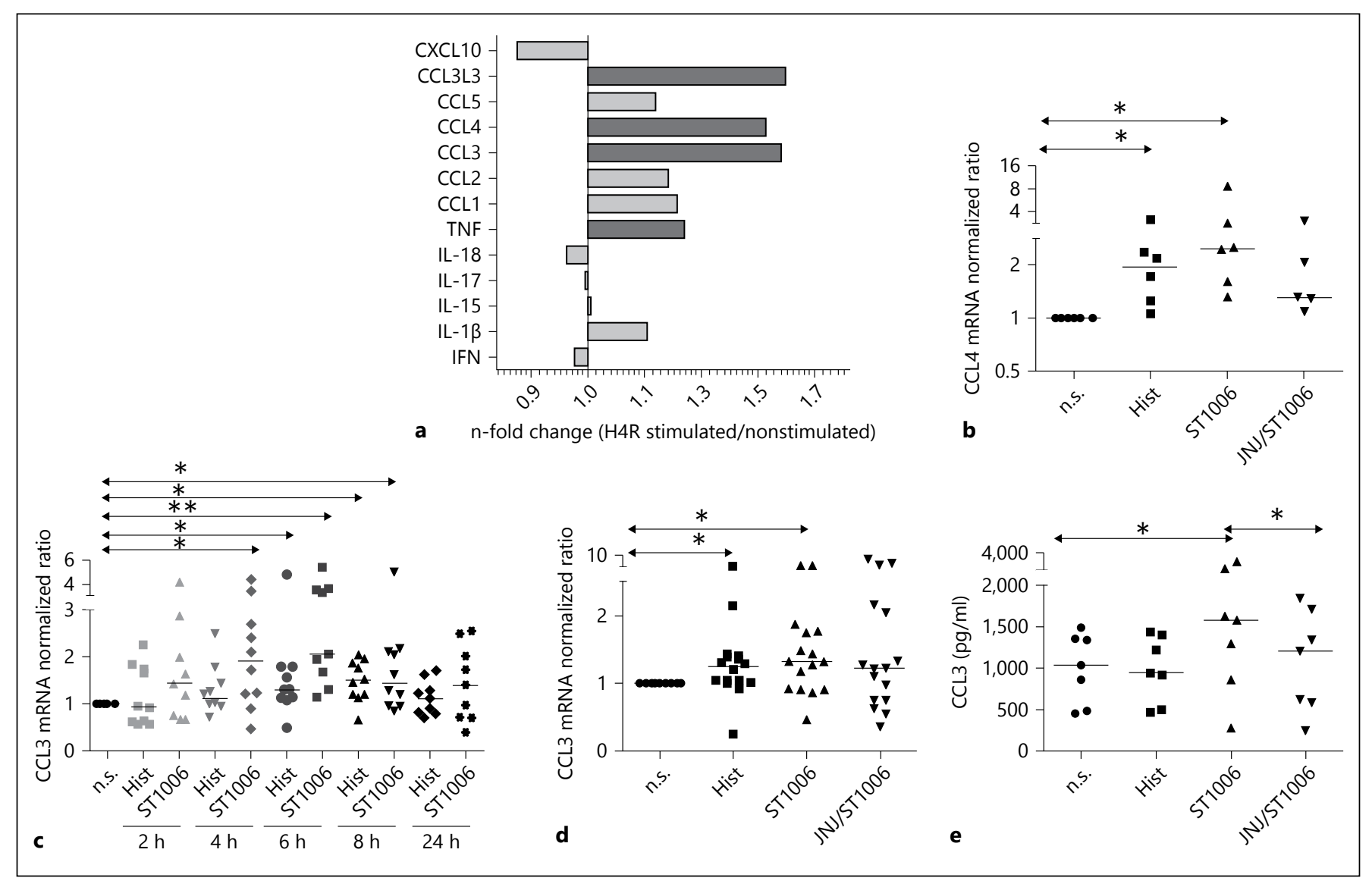

Fig. 2. a Selected targets, which play a role in activated NK cells, analyzed by microarray-based mRNA expression profiling in human NK cells. The average fold change from 2 experiments is shown. The $\mathrm{x}$-axis gives the relative mRNA expression of ST1006treated NK cells divided by untreated NK cells (fold change of mRNA expression of the ST1006-treated NK cells). The targets, which are illustrated with shaded columns, were quantified in further experiments. The medians are shown. $\mathbf{b}$ Treatment of human NK cells with histamine (Hist) and the H4R agonist ST1006 for $6 \mathrm{~h}$ significantly upregulates CCL 4 mRNA expression as assessed by quantitative real-time PCR. Individual values and medians of 5-6 experiments are depicted. n.s. $=$ Nonstimulated. $\mathbf{c}$ The upregulation of CCL3 mRNA expression occurs in a time-dependent manner and is increased after 4,6 and $8 \mathrm{~h}$ with a peak at $6 \mathrm{~h}$. NK cells were treat-

The discrepancy between CCL4 mRNA and protein expression in response to H4R stimulation compared to the concomitant mRNA and protein expression of CCL3 may occur due to differential secondary posttranscriptional regulation of these genes.

The pronounced secretion of CCL3 upon H4R stimulation might contribute to the accumulation of various innate and adaptive immune cells to the distinct microenvironment. NK cells themselves also demonstrated in- ed with histamine (Hist) and the H4R agonist ST1006 for different time periods as indicated. CCL3 mRNA expression was assessed by quantitative real-time PCR. Individual values and medians of 9-10 experiments are depicted. n.s. $=$ Nonstimulated. $\mathbf{d}$ Treatment of human NK cells with histamine (Hist) and the H4R agonist ST1006 for $6 \mathrm{~h}$ significantly upregulates CCL3 mRNA expression as assessed by quantitative real-time PCR. Individual values and medians of 16 experiments are depicted. n.s. = Nonstimulated. e The H4R significantly induces upregulation of the CCL3 protein as assessed by ELISA. This effect was significantly blocked by preincubation of the human NK cells with JNJ (JNJ7777120). The individual values and medians of 7 experiments are depicted. Only samples where the nonstimulated (n.s.) control showed $<1,500 \mathrm{pg} / \mathrm{ml}$ CCL3 protein were included in the study. ${ }^{*} \mathrm{p}<0.05 .{ }^{* *} \mathrm{p}<0.005$.

creased chemotactic responses to CCL3. Moreover, CCL3 has been identified to promote the cytolytic activity of polyclonal human NK cells or NK cell clones [16].

Taking into account these previous reports, our results suggest that the elevated expression levels of CCL3, which were mainly induced via activation of the H4R on NK cells, may exacerbate chronic inflammatory skin diseases by creating and maintaining the inflammatory response. 
In conclusion, our study on human NK cells provides a further contribution toward understanding the function of the H4R in distinct lymphocyte populations. In previous studies $[12,17]$, we showed inflammatory effects via the H4R on human CD4+ T cells and Th17 cells by upregulating the cytokines IL-31 or IL-17, respectively. In this regard, our findings here emphasize H4R antagonists as potential therapeutic tools to reduce the inflammatory response in allergic skin diseases.

\section{Acknowledgments}

The authors would like to thank Rebecca Albrecht and Eva Lina Fesefeldt for their excellent technical assistance.

This study was supported by grants from the Deutsche Forschungsgemeinschaft (DFG; Gu434/6-1).

\section{Disclosure Statement}

The authors declare no conflict of interest.

\section{References}

1 Jacobs R, Hintzen G, Kemper A, Beul K, Kempf S, Behrens G, Sykora KW, Schmidt RE: CD56 ${ }^{\text {bright }}$ cells differ in their KIR repertoire and cytotoxic features from CD56 ${ }^{\mathrm{dim}}$ NK cells. Eur J Immunol 2001;31:31213127.

-2 Moretta L, Montaldo E, Vacca P, Del Zotto G, Moretta F, Merli P, Locatelli F, Mingari MC: Human natural killer cells: origin, receptors, function, and clinical applications. Int Arch Allergy Immunol 2014;164:253-264.

$\checkmark 3$ Luci C, Gaudy-Marqueste C, Rouzaire P, Audonnet S, Cognet C, Hennino A, Nicolas JF, Grob JJ, Tomasello E: Peripheral natural killer cells exhibit qualitative and quantitative changes in patients with psoriasis and atopic dermatitis. Br J Dermatol 2012;166: 789-796.

4 Schmid-Ott G, Jaeger B, Adamek C, Koch H, Lamprecht F, Kapp A, Werfel T: Levels of circulating $\mathrm{CD}^{+} \mathrm{T}$ lymphocytes, natural killer cells, and eosinophils increase upon acute psychosocial stress in patients with atopic dermatitis. J Allergy Clin Immunol 2001;107: 171-177.

$\checkmark 5$ Ottaviani C, Nasorri F, Bedini C, de Pita O, Girolomoni G, Cavani A: CD56 ${ }^{\text {bright }} \mathrm{CD} 16^{-}$ NK cells accumulate in psoriatic skin in re- sponse to CXCL10 and CCL5 and exacerbate skin inflammation. Eur J Immunol 2006;36: 118-128.

-6 Simon D, Kozlowski E, Simon H: Natural killer T cells expressing IFN- $\gamma$ and IL-4 in lesional skin of atopic eczema. Allergy 2009;64: 1681-1684.

-7 Buentke E, Heffler LC, Wilson JL, Wallin RP, Lofman C, Chambers BJ, Ljunggren HG, Scheynius A: Natural killer and dendritic cell contact in lesional atopic dermatitis skin Malassezia-influenced cell interaction. J Invest Dermatol 2002;119:850-857.

8 Stander S, Steinhoff M: Pathophysiology of pruritus in atopic dermatitis: an overview. Exp Dermatol 2002;11:12-24.

-9 Petersen LJ, Hansen U, Kristensen JK, Nielsen H, Skov PS, Nielsen HJ: Studies on mast cells and histamine release in psoriasis: the effect of ranitidine. Acta Derm Venereol 1998;78:190193.

10 Ohtsu H: Pathophysiologic role of histamine: evidence clarified by histidine decarboxylase gene knockout mice. Int Arch Allergy Immunol 2012;158:2-6.

11 Damaj BB, Becerra CB, Esber HJ, Wen Y, Maghazachi AA: Functional expression of $\mathrm{H} 4$ histamine receptor in human natural killer cells, monocytes, and dendritic cells. J Immunol 2007;179:7907-7915.

12 Mommert S, Gschwandtner M, Koether B, Gutzmer R, Werfel T: Human memory Th17 cells express a functional histamine $\mathrm{H} 4$ receptor. Am J Pathol 2012;180:177-185.

13 Gschwandtner M, Koether B, Werfel T, Stark H, Gutzmer R: Profiling of histamine H4 receptor agonists in native human monocytes. Br J Pharmacol 2013;170:136-143.

14 Glatzer F, Mommert S, Köther B, Gschwandtner M, Stark H, Werfel T, Gutzmer R: Histamine downregulates the Th1-associated chemokine IP-10 in monocytes and myeloid dendritic cells. Int Arch Allergy Immunol 2014; 163:11-19.

15 Shrestha S, Nyaku M, Edberg JC: Variations in CCL3L gene cluster sequence and non-specific gene copy numbers. BMC Res Notes 2010;3:74.

16 Robertson MJ: Role of chemokines in the biology of natural killer cells. J Leukoc Biol 2002;71:173-183.

17 Gutzmer R, Mommert S, Gschwandtner M, Zwingmann K, Stark H, Werfel T: The histamine $\mathrm{H} 4$ receptor is functionally expressed on $\mathrm{T}_{\mathrm{H}} 2$ cells. J Allergy Clin Immunol 2009;123: 619-625. 